\title{
Perspectivas wittgensteinianas em pesquisas da Educação Matemática
}

Wittgensteinian perspectives in mathematical education researches

\author{
Marisa Rosâni Abreu da Silveira ${ }^{1}$ \\ Paulo Vilhena da Silva ${ }^{2}$
}

\section{Resumo}

O presente texto busca apresentar pesquisas no campo da Educação Matemática que adotam perspectivas de natureza linguística em suas investigações, em especial da filosofia da linguagem do filósofo austríaco Ludwig Wittgenstein. A despeito das particularidades de cada pesquisa, é possível notar pelo menos duas perspectivas diferentes: aquela que aposta num suposto relativismo wittgensteiniano, a fim de, entre outras coisas, defender a existência de várias matemáticas e colocar em suspeição a objetividade da matemática escolar e outra que vislumbra em Wittgenstein um aporte teórico para uma ênfase na importância do domínio de técnicas linguísticas, aprendidas por meio do ensino, do treino. Embora não haja consenso entre os comentadores das obras de Wittgenstein sobre se o pensador permite ou não interpretações relativistas de seus escritos, decidimos dar ênfase às pesquisas que se enquadram na segunda perspectiva, por acreditarmos que contribuem para a Educação, na medida em que se debruçam, entre outras coisas, na busca de mostrar como se aprende (ou porque não se aprende) matemática.

Palavras-chave: Educação Matemática. Filosofia da linguagem. Wittgenstein.

\section{Introdução}

Este texto tem o objetivo de discutir alguns conceitos da filosofia da linguagem de Wittgenstein, apontando como tais conceitos podem ser utilizados em pesquisas da Educação Matemática. A filosofia de Wittgenstein é compreendida, por seus comentadores, como o primeiro Wittgenstein, aquele do Tractatus logicophilosophicus e, o segundo refere-se aos seus escritos após 1933, época em que o filósofo tem como principal obra as Investigações filosóficas. Granger (1990) salienta que existe uma continuidade entre essas duas filosofias, pois Wittgens-

\footnotetext{
${ }^{1}$ Doutora em Educação, é professora associada ao Programa de Pós-Graduação em Educação em Ciências e Matemáticas da Universidade Federal do Pará, marisabreu@ufpa.br.

${ }^{2}$ Doutor em Educação Matemática, é professor do Instituto de Ciências Exatas e Naturais da Universidade Federal do Pará, paulovilhena1@gmail.com.
} 
tein teria retomado alguns conceitos da primeira para os esclarecer na segunda. As influências do filósofo austríaco não se restringem ao pensamento de alguns filósofos como aqueles pertencentes ao Círculo de Viena, mas também filósofos contemporâneos, tais como Jacques Bouveresse, Gilles Gaston-Granger e outros.

Como se sabe, Wittgenstein teve experiências como professor, mas suas ideias não tinham objetivos pedagógicos e sim filosóficos. Porém, conforme nos chama a atenção Macmillan (1995), seus escritos são do interesse de professores pelo fato de o filósofo ter refletido sobre como é possível ensinar ou aprender algo. Ao realizar seu trabalho filosófico, utiliza constantemente a imagem da criança para suas alusões e a do filósofo como seu interlocutor. Wittgenstein tem o interesse de investigar e dissolver alguns problemas filosóficos que podem ser gerados por falsas analogias e imagens enganosas.

Os cursos dados por ele em Cambridge, em 1939, por exemplo, mostram sua concepção de educação. Wittgenstein falava, na frente de seus alunos, aquilo que pensava sem consultar notas, convidando-os para responder perguntas e assim acirrando um diálogo constante. Quando lecionou para crianças em cidades no interior da Áustria elaborou junto aos seus alunos um dicionário com palavras e seus respectivos significados utilizados no contexto da região. Isso mostra a importância que Wittgenstein fornecia à linguagem, não apenas em sua filosofia, mas também em sua prática docente.

Na Educação Matemática podemos apontar um número não muito grande de pesquisadores que utilizam a filosofia de Wittgenstein como referencial teórico. A Educação Matemática brasileira também apresenta um número pequeno de adeptos a esta filosofia, considerando aquelas pesquisas que em sua maioria são da linha cognitivista. Alguns comentadores de Wittgenstein consideram o filósofo um relativista, mas isso não é consenso. Neste trabalho nos apoiamos naqueles comentadores que afirmam que Wittgenstein não é relativista, tais como Laugier (2008) e Oliveira (2016, p. 160) que finaliza sua pesquisa afirmando:

Podemos encaixar o pensamento de Wittgenstein em uma perspectiva que podemos chamar de "relativismo cultural moderado", visto que, no que diz respeito ao âmbito descritivo, ele não se encaixa de forma alguma em um re- 
lativismo extremo, do tipo "tudo vale", e, ao mesmo tempo, podemos situá-lo em uma perspectiva que pode ser chamada de "não relativismo ético", pois, para ele, a ética é absoluta, ou seja, ela é comum aos seres humanos (mas não no sentido essencialista de Platão).

As pesquisas em Educação Matemática do GELIM - Grupo de Estudos e Pesquisas do Programa de Pós-Graduação em Educação em Ciências e Matemática da Universidade Federal do Pará - versam sobre a linguagem e utilizam os conceitos wittgensteinianos, tais como jogos de linguagem, seguir regras, gestos ostensivos, semelhanças de família, ver e ver como. Assim, escolhemos ilustrar os conceitos da filosofia de Wittgenstein concentrados e aplicados nestas pesquisas na área da Educação Matemática, justamente porque não consideremos Wittgenstein um filósofo relativista. Nosso texto analisa brevemente esses conceitos de Wittgenstein e posteriormente os ilustra com pesquisas realizadas que focam o ensino e o aprendizado da Matemática.

\section{Alguns conceitos da filosofia de Wittgenstein}

\subsection{Os jogos de linguagem, a terapia filosófica, o uso e as formas de vida}

Apenas numa linguagem posso querer dizer algo com algo. (WITTGENSTEIN, 1999, p. 41).

A epígrafe pode parecer uma afirmação curiosa, óbvia, mas nos mostra parte das reflexões do filósofo austríaco, nas Investigações Filosóficas. Por exemplo, como é possível que alguém, ao proferir "lajota!", no contexto de uma obra de construção civil, queira pedir que tragam o objeto mencionado? Ou como se dá que compreendamos "cinco lajotas", ao ser proferido por nosso interlocutor, como um informe e não uma solicitação? Como alguém é capaz de distinguir os diferentes usos? Como veremos, a explicação desse fenômeno está no modo pelo qual nossa linguagem "opera". 
Em sua filosofia madura, Wittgenstein rejeitou a ideia de que a linguagem possuísse natureza ou objetivo únicos. No Tractatus Logico-Philosophicus o filósofo

Acreditava que tanto a linguagem quanto o mundo tinham uma estrutura lógica subjacente. A linguagem consistia de uma 'coleção de proposições', estas por sua vez eram compostas de nomes, os constituintes últimos da linguagem. Deveria haver uma correspondência entre linguagem e mundo: cada nome na linguagem nomearia (descreveria) um objeto no mundo e assim cada proposição da linguagem descreveria um fato no mundo. (SILVA; SILVEIRA, 2013, p. 126).

A concepção referencial de linguagem presente em seu primeiro livro denota um uso dogmático da linguagem, como se sua única função fosse a de descrever. Ao rejeitar a ideia de que a linguagem teria uma natureza única, o filósofo propõe a "cura" para uma "doença" presente na filosofia, a saber, os equívocos que são consequência do uso dogmático da concepção referencial de linguagem, por meio de um método que ele chama de "terapia filosófica".

A terapia de Wittgenstein visa liberar-nos do "enfeitiçamento" causado pela busca de essências extralinguísticas que expliquem o que é um dado conceito, reflexo da adoção de uma concepção referencial de linguagem. Ao negar os fundamentos últimos, paramos de buscar descobrir o que tal conceito é, e passamos a procurar enxergar como esse conceito é usado na linguagem ordinária. Essa mudança de perspectiva nos permite questionar algumas teorias pedagógicas vigentes, que se debruçam sobre o ensino da matemática, que buscam significados para os objetos matemáticos fora de sua linguagem, seja num mundo empírico ou mental.

Para exemplificar o modelo referencial de linguagem, nas Investigações, o filósofo cita um trecho das Confissões de Santo Agostinho, que reproduzimos a seguir:

Assim, pois, quando chamavam alguma coisa pelo nome, eu a retinha na memória e, ao se pronunciar de novo a tal palavra, moviam o corpo na direção do objeto, eu entendia e notava que aquele objeto era o denominado com a palavra que pronunciavam, porque assim o chamavam quando o desejavam mostrar. Que esta fosse sua intenção, era-me revelado pelos movimentos do corpo, que são como uma linguagem universal, feita com a expressão do ros- 
to, a atitude dos membros e o tom da voz, que indicam os afetos da alma para pedir, reter, rejeitar ou evitar alguma coisa. (AGOSTINHO, 1998, p. 98).

Segundo Wittgenstein, é possível destacar os fundamentos dessa concepção por meio dos enunciados: "as palavras da linguagem denominam objetos frases são ligações de tais denominações. - [...] cada palavra tem uma significação. Esta significação é agregada à palavra. É o objeto que a palavra substitui" $\left(1999, \S 01^{3}\right)$. Notamos também aqui, o papel dos gestos ostensivos na concepção referencial de linguagem. Em Agostinho, saber o significado de uma palavra consistiria em conhecer o próprio objeto que ela substitui, ou seja, o gesto ostensivo apontaria para algo exterior a linguagem. Assim o filósofo defende que essa concepção não compreende tudo aquilo que costumamos chamar de "linguagem" em seus mais variados usos, conforme esclarece:

É como se alguém explicasse: "Jogar consiste em empurrar coisas, segundo certas regras, numa superfície..." - e nós lhe respondêssemos: "Você parece pensar nos jogos de tabuleiro, mas nem todos os jogos são assim. Você pode retificar sua explicação, limitando-a expressamente a esses jogos". (1999, $\S 03)$.

Wittgenstein compara os usos da linguagem com os diversos uso de um conjunto de ferramentas: as ferramentas guardam semelhanças entre si, mas cada uma tem sua função. Tal analogia visa evidenciar que a linguagem, semelhante à uma caixa de ferramentas, é usada para diferentes propósitos e não possui uma finalidade única. Os diversos contextos de aplicação nos quais a linguagem está inserida são chamados por Wittgenstein de jogos de linguagem: "chamarei também de "jogos de linguagem" o conjunto da linguagem e das atividades com as quais está entrelaçada (1999, §07)”.

O termo "jogo de linguagem" deve aqui salientar que o falar da linguagem é uma parte de uma atividade ou de uma forma de vida. Imagine a multiplicidade dos jogos de linguagem por meio destes exemplos e outros: Comandar, e agir segundo comandos - [...] Relatar um acontecimento - Conjectiurar sobre

\footnotetext{
${ }^{3}$ Tendo em vista a existência de diversas traduções e edições dos livros de Wittgenstein, sempre que possível damos preferência para o número do aforismo e não o número da página, o que facilita a consulta do leitor interessado, independente da edição/tradução que possua.
} 
o acontecimento - Inventar uma história, ler - Representar treatro - [...] Pedir, agradecer, saudar, orar. (WITTGENSTEIN, 1999, §23).

Wittgenstein assente que o sentido de uma sentença não pode ser determinado sem levar em conta o contexto ou forma de vida ${ }^{4}$ na qual está imersa: "estamos falando do fenômeno espacial e temporal da linguagem, não de um fantasma fora do espaço e do tempo" (1999, §108). A significação de uma expressão linguística é (para uma grande classe da casos) seu uso na linguagem (1999, $\S 43)$.

Retomando as questões postas no início da sessão, podemos concluir que é graças ao contexto (o jogo de linguagem) que podemos compreender um ao outro. Ora, os jogos de linguagem estão imersos em nossas atividades rotineiras e é em sua aplicação que as palavras obtem significação. E esse emprego envolve uma entonação de voz particular, expressões faciais, gestos, etc. Nessa nova perspectiva filosófica apresentada por Wittgenstein, o gesto ostensivo faz parte da linguagem: o gesto ostensivo pode ser usado para tornar o objeto apontado uma amostra de uma dada palavra usada concomitantemente ao gesto de apontar. Portanto, o que torna possível entender o que o outro diz ou faz, é o mesmo "universo linguístico" que partilhamos (SILVA, 2011).

Importa notar, conforme veremos na sessão seguinte, que embora uma expressão linguística possua usos variados, isso não implica ambiguidade. Wittgenstein, assim, desenvolve uma critica a visão essencialista, mostrando que não há algo que esteja presente em todos os usos daquilo que denominamos jogo, o que explicaria o fato de empregarmos a mesma denominação para todos,.

\footnotetext{
${ }^{4}$ A cultura, as práticas, as tradições, os costumes e mitos. Segundo Glock (1998), é o entrecruzamento entre as atividades que partilhamos, a cultura, a visão de mundo e os usos da linguagem.
} 


\section{2 - Semelhanças de família}

Segundo o essencialismo ${ }^{5}$, é necessário que haja um traço presente em todos os casos de uso de uma expresão linguística, o que elucidaria o fato de todos serem abarcados pelo mesmo conceito. Para que um dado conceito - como o de jogo - pudesse ser assim chamado, este deveria possuir "limites" cristalinos, isto é, sua essência (SILVA, 2011).

Wittgenstein usava o conceito de semelhanças de família para assentar a similaridade geral entre os usos de expressões linguísticas e não a partilha de um conjunto de traços definidores. Ora, é verdade que uma mesma palavra pode designar várias atividades em diferentes contextos, mas isso não significa que o conceito que engloba essa palavra não tenha unidade.

Nas Investigações o filósofo é questionado por seu interlocutor, acusando-o de não apontar o que seria o essencial da linguagem e assim replica:

E isso é verdade - Em vez de indicar algo que seja comum a tudo aquilo que chamamos de linguagem, digo que não há uma coisa comum há esses fenômenos, em virtude da qual empregamos para todos a mesma palavra, - mas sim que estão aparentados uns com os outros de muitos modos diferentes. $E$ por causa desse parentesco ou desses parentescos, chamamo-los todos de "linguagens". (WITTGENSTEIN, 1999, §65).

Para exemplificar, Wittgenstein disserta sobre as atividades as quais denominamos de jogos (de tabuleiros, de cartas, de bola etc.). O pensador nos convida a meditar a respeito das semelhanças e diferenças entre os mais variados tipos de jogos: são todos lúdicos? Não da mesma maneira que a amarelinha e o xadrez. Há sempre um ganhar e perder? Não se imaginarmos uma criança que apenas joga uma bola na parede e apanha novamente. E quanto a habilidade ou criatividade, tem o mesmo aspecto em jogos como xadrez ou futebol? E assim o teórico conclui:

E tal é o resultado desta consideração: vemos uma rede complicada de semelhanças, que se envolvem e se cruzam mutuamente. Semelhanças de con-

\footnotetext{
5 "Corrente de pensamento introduzida e defendida por Aristóteles segundo a qual a pesquisa científica deve penetrar até a essência das coisas para poder explicá-las" (ABBAGNANO, 2007, p.363).
} 
junto e de pormenor. Não posso caracterizar melhor essas semelhanças do que com a expressão "semelhanças de família"; pois assim se envolvem e se cruzam as diferentes semelhanças que existem entre os membros de uma família: estatura, traços fisionômicos, cor dos olhos, o andar, o temperamento etc., etc. - E digo: os jogos formam uma família. (WITTGENSTEIN, 1999, §66-67).

Conforme relata o filósofo, costumamos acreditar que há algo comum a tudo aquilo que chamamos de "jogo", o que justificaria chamarmos todos de jogos, mas, como vimos, "os jogos formam uma família, cujos membros tem semelhanças de família. Alguns deles têm o mesmo nariz, outros as mesmas sobrancelhas e outros, ainda, a mesma maneira de andar, e essas semelhanças se sobrepõem umas às outras" (WITTGENSTEIN, 1998, p. 17). Segundo Wittgenstein é em razão dessa unidade que costumamos falar do conceito de jogo, do conceito de número etc. $(1999, \S 68,70)$ e não de diversos conceitos de jogo ou número.

Cada situação de emprego do conceito revela uma parcela, um aspecto do significado. Os usos que fazemos a tudo que denominamos de número, por exemplo, seja número real, racional, número de canetas ou metros, cada um revela uma parcela6 do conceito de número. (SILVA; SILVEIRA, 2013, p. 129).

Apesar dos diferentes usos que um conceito definido por semelhanças de família possa possuir, isso não implica ambiguidade ou caos: sabemos usá-los sem grandes confuseões e somos capazes de compreendermos uns aos outros.

Poder-se-ia argumentar que a criação de novos usos para um conceito que já usamos, nos daria um novo conceito modificado. Porém, conforme esclarecem Baker e Hacker (2005, p. 214), "o conceito de "arte", por exemplo, expandiu-se para incluir novos parentes como o cinema, a fotografia e o balé, sem nenhuma mudança no significado da palavra 'Arte'” (BAKER; HACKER, 2005, p. 214). Ora, quando algo assim ocorre, o conceito se expande com o acolhimento de novos "familiares", o que não nos dá um novo conceito, mas representa o alargamento do conceito em questão.

\section{3 - O seguir regras, a compreensão e o ver-como}

Um dos temas mais discutidos sobre a obra de Wittgenstein é o seguir regras. Em seus escritos, o filósofo refletia a respeito de como ocorre que alguém 
possa compreender e seguir regras ou como uma regra (seja um fórmula matemática ou uma placa de trânsito) implicaria sua correta aplicação, uma vez que poder-se-ia, de algum modo, interpretar qualquer forma de agir como em conformidade com a regra: "se cada modo de agir deve estar em conformidade com a regra, pode também contradizê-la. Disto resultaria não haver aqui nem conformidade nem contradições" (WITTGENSTEIN, 1999, §201). Entre outros exemplos, o filósofo discute essa questão indagando sobre a possibilidade de alguém se orientar por indicadores de direção, continuar uma série númerica ou mesmo compreender 0 ato de apontar para algo.

Ora, como as explicações do mestre seriam suficientes para que o aprendiz pudesse continuar a série dos números naturais, por exemplo, se ela é infinita, diferente das instruções e exemplos finitos que fornecemos? Segundo Wittgenstein (1999), nossa tendência é crer que uma regra, de alguma maneira, contém em si suas possibilidades de aplicação, o que implicaria que o contexto de aplicação não influenciaria na significação de uma expressão linguística. Porém, uma seta (em um indicador de direção) não aponta por um passe de mágica, mas sim pelo uso que adotamos fazer dela; tampouco uma série numérica contém em si o modo correto de continuá-la, uma vez que precisamos aprender como convencionamos prosseguir, isto é: "todo signo sozinho parece morto. O que lhe dá vida? No uso ele vive” (WITTGENSTEIN, 1999, §432).

Como vemos, a correta aplicação de uma regra depende de critérios públicos convencionados por seus usuários, isto é, de nossos hábitos, costumes, de nossas instituições, que são aprendidas, e isso explica porque compreendemos um gesto ostensivo ou a continuação de uma série numérica. Conforme assinala o filósofo austríaco:

Fui treinado para reagir de uma determinada maneira a este signo e agora reajo assim". (WITTGENSTEIN, 1999, §198) [...]. Seguir uma regra, fazer uma comunicação, dar uma ordem, jogar uma partida de xadrez são hábitos (costumes, instituições) (WITTGENSTEIN, 1999, §199).

Conforme apontam Baker e Hacker (2005) - comentadores das ideias de Wittgenstein -, se buscassemos onde se localiza a compreensão, seja de uma 
série numérica ou das técnicas relacionadas a pintura, por exemplo, esta seria encontrada junto das habilidades ou capacidades. Destarte, a compreensão de uma regra e sua aplicação em diferentes situações não dependem de uma intuição que nos vem de golpe ou de um suposto processo mental misterioso, mas sim de uma habilidade que desenvolvemos por meio do aprendizado (SILVA, 2011).

Assim, compreender ou não compreender algo de ter ou não aprendido as técnicas relacionadas ao bom desempenho nas atividades relacionadas ao que se compreende: "compreender uma frase significa compreender uma linguagem. Compreender uma linguagem significa dominar uma técnica" (WITTGENSTEIN, 1999, §199). Segundo o filósofo, o que muitas vezes nos intriga é como passamos da incompreensão para a compreensão, como se algo oculto ocorresse em nossa alma.

Algumas vezes, ao subitamente compreendermos algo, como a lei de uma série numérica, ou ao notar um aspecto diferente em uma figura ambígua, dizemos "agora eu sei", "agora eu compreendo", "agora eu vejo" ou ainda "agora eu posso!" e temos a impressão de que algo misterioso aconteceu em nossa mente. Entretanto, compreender algo de repente marca uma mudança: da incompreensão à compreensão, portanto, de não ser capaz de fazer certas coisas a ser capaz de fazê-las. "Agora eu compreendo", "agora eu vejo" ou "agora eu sei" representa o "nascimento" de uma habilidade (SILVA; SILVEIRA, 2014, p. 26).

Compreender algo subitamente nos leva a relembrar outro conceito wittgensteiniano, a saber: o de ver-como. O que se dá quando, ao olharmos para uma figura, conseguimos vê-la ora como uma coisa, ora como outra? É o caso, por exemplo, das figuras ambíguas, como a "lebre-pato" ou da moça jovem-idosa. Por vezes somos capazes de ver apenas o pato (a idosa) e de repente conseguimos visualizar a lebre (a jovem). Temos a impressão que algo misterioso aconteceu em nosso íntimo, pois é como se a imagem tivesse se modificado, mas sabemos que é a mesma! Como explicar?

Segundo Wittgenstein, ver algo como outra coisa, isto é, notar diferentes aspectos em uma figura é semelhante ao caso da vivencia da significação, isto é, notar diferentes aspectos em uma figura se assemelha a dominar diferentes usos 
de uma mesma palavra, daí que "assim como compreender os diferentes empregos de uma palavra depende do domínio de suas regras de uso, notar os aspectos em uma figura depende do domínio de técnicas" (SILVA; SILVEIRA, 2014, p. 25).

Portanto, notar os diferentes aspectos em uma figura ambígua, assim como compreender algo, implica ter uma habilidade, implica dominar técnicas linguísticas. Conforme Wittgenstein: "a gramática da palavra "saber" está, evidentemente, intimamente aparentada com a de "poder", "ser capaz de". Mas também estreitamente aparentada com a da palavra "compreender". ('Domínio' de uma técnica)" (1999, §150), ou seja, quem compreende algo desenvolve um "saber-fazer" e assim é capaz de levar a cabo determinadas tarefas que se relacionam com o que se compreende.

\section{Pesquisas na Educação Matemática com enfoque na filosofia}

\section{da linguagem de Wittgenstein}

As pesquisas em Educação Matemática com enfoque na Filosofia da Linguagem de Wittgenstein vem crescendo, principalmente no Programa de PósGraduação em Educação em Ciências e Matemática da Universidade Federal do Pará. Estas pesquisas em Educação Matemática deste programa se diferem daquelas que tratam Wittgenstein como um filósofo relativista, como também associam sua filosofia aos estudos culturais ou a filósofos pós-modernos. Silveira (2017) em seu texto intitulado Jogos de linguagem entre professor e alunos: possibilidades de aprender e ensinar matemática destaca algumas dessas pesquisas que utilizam o conceito de jogos de linguagem, dentre elas, encontramos a pesquisa de Moreira (2015) que analisou como podem ocorrer jogos de linguagem entre alunos surdos e alunos ouvintes quando tentam compreender conceitos matemáticos. Nesta pesquisa, o professor da turma investigada era auxiliado por um profissional intérprete que traduzia em sinais suas palavras ditas aos alunos para explicar os conteúdos matemáticos. A autora mostra que os alunos surdos buscam estratégias linguísticas, tais como a comunicação com alguns alunos ouvin- 
tes na busca de compreender aquilo que o professor de matemática ensina. É então na negociação entre estas diferentes vozes, - do professor, do intérprete e dos colegas ouvintes - que os alunos surdos compreendem conceitos matemáticos. Para os alunos surdos, a tradução da linguagem do professor para a Libras, estabelecida pelo intérprete, não é suficiente para a compreensão dos conceitos matemáticos explicados pelo professor e, assim, recorrem aos colegas ouvintes, por mais explicações, justamente pelo motivo de a linguagem matemática ser como a Língua Portuguesa, ou seja, outra linguagem que Ihes aparenta ser estrangeira, pois difere de sua língua materna.

Outra pesquisa que trabalhou o conceito de jogos de linguagem de Wittgenstein é a de Melo (2013) que analisou os jogos de linguagem entre a Matemática e a Informática para o ensino e a aprendizagem da função quadrática com o auxílio do software Geogebra. O autor mostra que o comportamento gráfico da função pode ser mais bem explorado, já que o professor não dispõe de tempo suficiente para fazer o aluno perceber todas as nuances sob a influência da alteração dos coeficientes da função e seus respectivos gráficos. Assim, a utilização de jogos de linguagem pelo professor para ensinar a função quadrática aos alunos, ora usando o quadro de escrever, ora usando o software auxilia na compreensão do conceito de função quadrática. A informática, nesta perspectiva, busca complementar aquilo que o professor pode ter dificudades em executar, ou seja, transforma funções em gráficos, permitindo que o aluno perceba o movimento da parábola de acordo com as mudanças dos coeficientes da função. Estes jogos de imagem possibilitam a compreensão do comportamento gráfico da função em um espaço de tempo possível, já que diferentes tarefas podem ser executadas em sala de aula. Assim, o jogo de linguagem da informática estabelecido fornece sentido às funções quadráticas trabalhadas nas aulas de Matemática.

A proposta de utilizar jogos de linguagem por professores em sala de aula mostra a preocupação de buscar compreender aquilo que os alunos estão interpretando de suas explicações no ensino de determinados conceitos matemáticos. Tanto Silva (2015), quando pretendia analisar como se dão os jogos de linguagem 
entre os alunos e a professora no processo de alfabetização quanto Costa (2015), quando buscava compreender como o aluno surdo aprende conceitos matemáticos ao traduzir da linguagem matemática para a língua de sinais, perceberam que o ensino estava sendo pautado no modelo referencial da linguagem. Na pesquisa de Silva (2015), a professora alfabetizadora associava a cada numeral uma quantidade de objetos e na pesquisa de Costa (2015), o professor associava a cada palavra da Língua Portuguesa um sinal em Libras. Em todos os dois modos de ensino, as palavras eram como que etiquetas para objetos ou para sinais. De acordo com Wittgenstein (1999), sabemos que não existe um sentido único e fixo que podemos fornecer a uma palavra, pois o sentido pode mudar de acordo com o contexto em que tal palavra está sendo utilizada.

A linguagem matemática é composta de códigos e precisa ser traduzida para a linguagem materna do aluno para que o texto matemático tenha sentido. Wittgenstein $(1999, \S 23)$ afirma que traduzir de uma língua para outra é um jogo de linguagem. Nesse sentido, a pesquisa de Costa (2015) aponta para a dificuldade de tradução da linguagem matemática para a língua de sinais justamente porque muitos objetos matemáticos ainda não têm um sinal correspondente. $\mathrm{Na}$ mesma linha teórica, a pesquisa de Monteiro (2016), quando destaca as possibilidades e impossibilidades de tradução no ensino da matemática na educação escolar indígena, aponta para novas formas de perceber o mundo indígena, suas formas de vida em meio à linguagem matemática e a Língua Portuguesa.

Barros (2012) analisou se os conceitos matemáticos que o aluno do programa projovem urbano utiliza no cotidiano são os mesmos que ele utiliza em sala de aula e percebeu semelhanças de família, ou seja, algumas divergências e convergências entre a matemática fora e dentro da escola. As estratégias utilizadas no cotidiano, tais como o cálculo mental e as estimativas ou aproximação de valores, nem sempre coincidem com o que se espera no ambiente escolar. No cotidiano ocorrem negociações por meio de diálogo e acordos entre os participantes da negociação de compra e venda de mercadorias que são estratégias para resolver problemas matemáticos que não são utilizadas na escola. Nesse sentido, pode- 
mos afirmar que existem semelhanças de família entre os cálculos utilizados na escola e na vida cotidiana, como também que

O conhecimento da matemática foi elaborado historicamente pela sociedade em meio as experiências empíricas, com o passar do tempo este saber se cristaliza em normas que não podem mais ser modificadas, porém quando aplicadas no cotidiano ficam atreladas a fenômenos antropológicos. (SILVEIRA; CUNEGATTO, 2016, p.1).

A Matemática da sala de aula é diferente daquela aplicada ao cotidiano justamente porque ela é normativa. A Matemática na empiria pode ser negociada. Digamos que duas maçãs grandes mais três maçãs pequenas sejam consideradas cinco maçãs iguais. Dizer que os homens acreditam que 2 maçãs grandes + 3 maçãs pequenas fazem cinco maçãs iguais é um fenômeno antropológico. No entanto $2+3=5$ é uma norma, uma regra gramatical. Nesse sentido, Wittgenstein afirma que

"Se somamos 2 coisas a 3 coisas, daí podem resultar diferentes quantidades de coisas. Mas consideramos como norma o processo de que 3 coisas e 2 coisas fazem 5 coisas. Entendes? Assim é como resultam 5".

Não poderia dizer-se à criança: "Mostra-me como 3 e 2 dão 5?" Ante o qual a criança calcularia no ábaco $3+2$.

Se na lição de cálculo se pergunta à criança: "Como resulta 5 de $3+2$ ?" - O que ela tem que demonstrar? Bom, evidentemente, há de reunir 3 bolas e 2 bolas e contá-las (ou algo semelhante).

[...] E se a criança mostra agora como 3 e 2 dão 5, mostra um procedimento que pode ser considerado como fundamento da regra " $2+3=5$ " (WITTGENSTEIN, 1987, parte VI, § 9).

$\mathrm{Na}$ Educação, o professor utiliza diferentes metodologias para auxiliar a ilustrar o objeto de aprendizagem. Oliveira (2018) investigou a utilização de gestos ostensivos no ensino de conceitos matemáticos para uma compreensão sobre a explicação e a compreensão desses conceitos. A pesquisa teórica utilizou exemplos de situações de ensino extraídos de documentos oficiais de orientações curriculares, de livros didáticos e da prática docente do pesquisador. Oliveira afirma que o gesto ostensivo, para Wittgenstein é um instrumento linguístico que nos permite estabelecer uma ligação interna entre uma palavra e o objeto para o qual apontamos. A análise do material da coleta de dados mostrou que o gesto ostensivo pode favorecer a compreensão de conceitos matemáticos, na medida em 
que, se configura como um meio de apresentação de convenções linguísticas, porém, pode também causar mal-entendidos quando é apresentado de maneira ambígua.

No ensino ostensivo, para o aprendizado de palavras e conceitos, podemos salientar que

A questão da nomeação será desmembrada e apresentada sob dois aspectos. Primeiro, os pontos de contato elementares da linguagem com a realidade, que serão, agora, atribuídos a técnicas de ensino ostensivo, ou de adestramento, inseridas em situações que orientam a sua aplicação, isto é, as lições (Unterricht) de que fala Wittgenstein (IF, § 6). São essas lições que permitem interpretar os gestos ostensivos e as repetições de palavras, e aplica-los seja para adestrar o comportamento, seja para associar imagens mentais a objetos, seja mesmo para facilitar a compreensão da palavra (IF § 6) (MORENO, 2012, p. 83).

Nesse sentido, Wittgenstein ao afirmar que "ensinar uma linguagem aqui não é explicar, mas antes é adestrar" (2005, p. 39) está querendo salientar que inserir o aluno em um ambiente favorável ao uso de determinadas palavras se evidencia quando os exercícios passam por diferentes aplicações, de modo que os exercícios em diferentes contextos constituem uma espécie de treino. A pesquisa de Gonçalves (2013) aponta para esta necessidade de desenvolver técnicas que instrumentalizem o aprendiz ao domínio de tais técnicas de aplicação de regras matemáticas. Adestrar, neste contexto, significa colocar o aluno em diferentes âmbitos de aprendizagem de uma determinada regra, prover o aluno com diferentes tipos de exercícios com a finalidade de fazer perceber as nuances de uma aplicação da regra num e noutro exercício.

Os conceitos de ver e ver- como da filosofia de Wittgenstein foram analisados por Silva e Silveira (2014) que apontam para o significado compreendido no uso das palavras, signos ou regras destacando desta forma um domínio de técnicas tal como, por exemplo, ver a diagonal de um retângulo como a hipotenusa de um triângulo retângulo. O significado como uso na Filosofia da Linguagem de Wittgenstein nos ajuda a compreender o conceito de ver-como não como um processo mental, mas como o domínio de técnicas que podem ajudar a esclarecer algumas questões sobre a visualização no aprendizado da Matemática. Existem 
muitas maneiras de ver um objeto, nesse sentido, Schmitz (1988) afirma que a visão deve ser educada por meio da gramática do ver, ver no sentido de perceber, faz eco com o pensamento. Ver o aspecto de um objeto envolve uma parte visual e uma parte de interpretação.

O conceito de seguir regras da filosofia de Wittgenstein podemos encontrar na pesquisa de Silva (2011) que analisou a aplicação do algoritmo da divisão e concluiu que o professor não pode prever novos contextos de uso pelo estudante. Assim, o autor alerta que não há garantia de que não haverá mal-entendidos, já que as regras não estão imunes a equívocos. Meira (2012) ao analisar o uso da regra de três simples e composta mostra que a estratégia utilizada pelo professor fez com que o conceito de regra de três não fosse bem compreendido pelos alunos, já que o professor criou uma regra própria que não convergia com as explicações de livros didáticos.

Teixeira Junior (2016) em sua pesquisa utiliza a epistemologia do uso de Arley Moreno em contribuição a terapia de Wittgenstein para compreender as confusões conceituais no ensino da Álgebra. O autor percebe que a concepção referencial e essencialista da linguagem está presente na maioria do material analisado, tais como livros didáticos, dissertações e teses, bem como nos documentos oficiais. Porém, para o autor, a Álgebra se constrói como linguagem e a partir da epistemologia do uso pode ser entendida como uma gramática autônoma, arbitrária e com relações internas de sentido. Pesquisas como essa podem contribuir com a educação matemática, pois algumas verdades tácitas forjadas por teorias educacionais podem ser colocadas em suspeição. Nesse sentido Gottschalk (2017) salienta

De que modo o professor "terapeuta" pode levar o aluno a uma atitude similar, a saber, como introduzir novas perspectivas e diferentes pontos de vista que venham a substituir as imagens que o aluno traz para dentro da escola, de modo a persuadi-lo, e não necessariamente convencê-lo, a mudar sua maneira de considerar determinadas situações? E mais, como vencer as barreiras da vontade do aluno, sem coagi-lo para tal? Como intervir na vontade do aluno? (GOTTSCHALK, 2017, p. 140). 
Como podemos ver, longe de serem discussões que interessam apenas a filósofos, os conceitos wittgensteinianos trazem luz às várias questões de ensino e de aprendizado, em particular na Matemática. Não é surpresa, portanto, que as ideias desse pensador venham ganhando espaço na Educação Matemática, tendo diferentes interpretações e contribuições.

\section{Considerações finais}

Vimos que os conceitos de jogos de linguagem, semelhança de família, ver e ver-como, seguir uma regra, traduzir de uma língua para outra, gesto ostensivo e a própria terapia filosófica de Wittgenstein contribuem com a Educação Matemática. Para nossa análise, tratamos as pesquisas do Grupo de Estudos e Pesquisas em Linguagem Matemática do Programa de Pós-Graduação em Educação em Ciências e Matemática da Universidade Federal do Pará como forma de apontarmos para os diversos conceitos de Wittgenstein aplicados à Educação Matemática. Todas estas pesquisas trabalham com conceitos de Wittgenstein numa perspectiva não relativista e diferem daquelas que compartilham as ideias do filósofo austríaco com autores ditos pós-modernos. Reconhecemos, assim, que os conceitos que envolvem a linguagem favorecem na análise das palavras ditas em sala de aula, seja pelo professor ou pelo aluno. As regras ensinadas e aprendidas, bem como as palavras empregadas para ensinar tais regras. O exercício de uso das palavras e de regras para a compreensão de conceitos matemáticos evidencia o caráter linguístico e não a compreensão de processos mentais dos aprendizes, como buscam os cognitivistas. O gesto do professor para apontar para o aspecto do objeto que pretende salientar, assim como a observação de que o aspecto apontado esteja tão claro como uma definição. A educação do modo de ver objetos matemáticos em diferentes perspectivas pelo aluno deve ser estimulada, ver ora de uma forma, ora de outra forma. As imagens são conceitos, assim, trabalhar imagens associadas aos seus respectivos conceitos pode oferecer forma de vida aos conceitos ensinados. 
Embora não haja um consenso a respeito da compreensão das ideias wittgensteinianas, as pesquisas aqui mencionadas nos dão uma panorâmica de como utilizar os conceitos da filosofia da linguagem de Wittgenstein na Educação Matemática, mas essas são as primeiras, outras virão e quem sabe nossos estudantes, com este novo enfoque, aprendam com maior sucesso os conceitos matemáticos que pretendemos ensinar.

\section{Referências}

ABBAGNANO, Nicola. Dicionário de filosofia. São Paulo: Martins Fontes, 2007.

AGOSTINHO, Santo. Confissões. São Paulo: Paulinas, 1998.

BAKER, Gordon; HACKER, Peter. Wittgenstein: understanding and meaning - part I. Oxford: Blackwell, 2005.

BARROS, Otávio Augusto do Espírito Santo. O Saber Cotidiano no Ensino de Matemática: Rupturas no Aprendizado dos Alunos do Projovem Urbano. Belém: Universidade Federal do Pará, 2012. Dissertação de Mestrado em Educação Matemática.

COSTA, Walber Christiano Lima da. Tradução da linguagem matemática para a libras: jogos de linguagem envolvendo o aluno surdo. Dissertação (Mestrado) - Universidade Federal do Pará, Instituto de Educação Matemática e Científica, Programa de PósGraduação em Educação em Ciências e Matemáticas, Belém, 2015.

FANN, K. T. Wittgenstein's Conception of Philosophy. California: Blackwell, 1971.

GONÇALVES, Carolina Fragoso. ADESTRAR PARA A AUTONOMIA: a crítica

wittgensteiniana ao construtivismo. Dissertação (Mestrado) - Universidade Estadual do Norte Fluminense Darcy Ribeiro. Programa de Pós-Graduação em Cognição e Linguagem do Centro de Ciências do Homem, Campos dos Goytacazes - RJ, 2013.

GLOCK, Hans-Johann. Dicionário Wittgenstein. Tradução de Helena Martins. Rio de Janeiro: Jorge Zahar Editor, 1998.

GOTTSCHALK, Cristiane Maria Cornélia. Os rituais educacionais à luz da filosofia da linguagem de Wittgenstein. Sophia, Colección de Filosofía de la Educación, n. 22, 2017, pp. 125-144.

GOUTEFANGEA, Patrick. Alan Turing: la "pensée" de la machine et l'idée de pratique. Philosophie. Université de Nantes, 1999. Français. Disponível em: https://tel.archivesouvertes.fr/ tel-01298350. Acesso em 23/02/2018. 
GRANGER, Gilles-Gaston. Invitation à la lecture de Wittgenstein. Aix-en-Provence: Editions Alinea, 1990.

MACMILLAN, C. J. B. "How not to Learn: Reflections on Wittgenstein and Learning". In: Philosophy and Education: Accepting Wittgenstein's Challenge. Eds.: Paul Smeyers e James D. Marshall, vol. 6, Kluwer Academic Publishers, 1995, pp.161-169.

LAUGIER, Sandra. Sciences du vivant et phénoménologie de la vie. Règles, formes de vie et relativisme chez Wittgenstein. Noesis. n. 14, 2008. pp. 41-80. Disponível em: http://noesis.revues.org/1652. Acesso em 24/02/2018.

MEIRA, Janeisi de Lima. Labirintos da compreensão de regras matemáticas: um estudo a partir da regra de três. Belém: Universidade Federal do Pará, 2012. Dissertação de Mestrado em Educação Matemática.

MELO, Luciano Augusto da Silva. Dois jogos de linguagem: a Informática e a Matemática na aprendizagem de Função Quadrática. Dissertação (Mestrado em Educação em Ciências e Matemáticas) - Universidade Federal do Pará, 2013.

MONTEIRO, Hélio Simplício Rodrígues. O ensino de matemática na educação indígena: (Im)Possibilidades de Tradução. Campinas: Unicamp, 2016. Tese de Doutorado.

MOREIRA, Ivanete Maria. Os jogos de linguagem entre surdos e ouvintes na produção de significados de conceitos matemáticos. (Tese de Doutorado) - Universidade Federal do Pará, Instituto de Educação Matemática e Científica. Programa de PósGraduação em Educação em Ciências e Matemáticas, 2015.

MORENO, Arley Ramos. Introdução a uma epistemologia do uso. CADERNO CRH, Salvador, v. 25, n. 2, p. 73-95, 2012.

OLIVEIRA, Marcelo de Sousa. A utilização de gestos ostensivos no ensino de conceitos de conceitos matemáticos: uma interpretação à luz da filosofia de Wittgenstein, 2018. Belém: Universidade Federal do Pará. Tese de Doutorado em Educação em Matemática.

OLIVEIRA, Valdomiro. Linguagem, ética e relativismo em Wittgenstein. Florianópolis: UFSC, 2016. Dissertação de Mestrado. 166p.

SCHMITZ, François. Wittgenstein, la philosophie et les mathématiques. Paris: PUF, 1988.

SILVA, Carlos Evaldo. Concepções de significado: implicações no ensino da matemática na alfabetização. Dissertação (Mestrado) - Universidade Federal do Pará, Instituto de Educação Matemática e Científica, Programa de Pós-Graduação em Educação em Ciências e Matemáticas, 2015.

SILVA, Paulo Vilhena da. 0 aprendizado de regras matemáticas: uma pesquisa de inspiração wittgensteiniana com crianças da 4aㅗ série no estudo da divisão. Belém: UFPA. Dissertação (Mestrado em Educação Matemática), 2011. 
SILVA, Paulo Vilhena da; SILVEIRA, Marisa Rosâni Abreu da. Matemáticas ou diferentes usos da Matemática? Reflexões a partir da filosofia de Wittgenstein. Acta Scientiarum. Educacion, Maringá, v. 35, n. 1, p. 125-132, 2013.

SILVA, Paulo Vilhena da; SILVEIRA, Marisa Rosâni Abreu da. O ver-como wittgensteiniano e suas implicações para a aprendizagem da Matemática: um ensaio. Boletim online de Educação Matemática, Joinville, v. 2, p. 17-34, 2014.

SILVEIRA, Marisa Rosâni Abreu da. Jogos de linguagem entre professor e alunos: possibilidades de aprender e ensinar matemática. UNIÓN (SAN CRISTOBAL DE LA LAGUNA), v. 50, pp. 78-91, 2017.

SILVEIRA, Marisa Rosâni Abreu da; CUNEGATTO, Thaís. Por uma Antropologia da Educação Matemática. Perspectivas da Educação Matemática, Mato Grosso do Sul, v. 8. n. 19, 2016, pp. 39-55.

SOUSA. Bárbara Nivalda Palharini Alvim. A Matemática em atividades de modelagem matemática: uma perspectiva wittgensteiniana. Londrina: UEL, 2017. Tese de Doutorado.

TEIXEIRA JUNIOR, Valdomiro Pinheiro. A terapia de Wittgenstein e o ensino da álgebra. Belém: UFPA. Tese de Doutorado, 2016.

WITTGENSTEIN, Ludwig. Investigações filosóficas. Tradução de José Carlos Bruni. São Paulo: Nova cultural, 1999.

WITTGENSTEIN, Ludwig. Observações Filosóficas. Tradução de Adail sobral e Maria Stela Gonçalves. São Paulo: Loyola, 2005.

WITTGENSTEIN, Ludwig. Observaciones sobre los fundamentos de la matemática. Madrid: Alianza Editorial, 1987.

WITTGENSTEIN, Ludwig. The Blue and Brown books. Oxford: Blackwell, 1998.

WITTGENSTEIN, Ludwig. Tractatus Logico-philosophicus. Tradução de Luiz Henrique Lopes dos Santos. São Paulo: Edusp, 1993. 